\title{
Proterozoic carbon isotope excursions driven by mantle recycling of carbon
}

\author{
JAMES EGUCHI $^{1}$, TIMOTHY LYONS ${ }^{1}$
}

${ }^{1}$ University of California, Riverside, 900 University Ave, Riverside, CA 92521; james.eguchi@ucr.edu, timothyl@ucr.edu

The geologic record shows that $\delta^{13} \mathrm{C}$ of marine carbonates has experienced excurions during times of important biological and environmental evolution, including fundamental steps in atmospheric oxygenation. $\delta^{13} \mathrm{C}$ excursions are often interpreted as changes in $f_{\text {org }}$, assuming $\delta^{13} \mathrm{C}$ of volcanic $\mathrm{CO}_{2}$ emissions have remained constant at $\sim-5 \%$. A recent study proposed that the Lomagundi $\mathrm{C}$ isotope excursion may have been the result of increased $\delta^{13} \mathrm{C}$ of volcanic $\mathrm{CO}_{2}$ emissions, rather than increased $f_{\text {org }}$ [1]. The authors proposed that the Great Oxidiation and Lomagundi events were the result of increased volcanic $\mathrm{CO}_{2}$ emissions that led to increased deposition of both organic $\mathrm{C}$ and carbonates due to enhanced continental weathering. This resulted in oxygen accumulation in the atmosphere due to the sequestration of organic $\mathrm{C}$ and a positive carbon isotope excursion via rapid release of heavy, carbonate-derived $\mathrm{CO}_{2}$ at arc volcanoes and the delayed release of light, organic Cderived $\mathrm{CO}_{2}$ at plume-fed volcanoes.

Here, we explore how the system responds to changes in the strength of the weathering feedback in addition to changes in volcanic $\mathrm{CO}_{2}$ fluxes. Results show that in response to increased weathering feedbacks, atmospheric oxygen levels increase by several orders of magnitude via enhanced organic $\mathrm{C}$ burial, and $\delta^{13} \mathrm{C}$ increases to $\sim+15 \%$ and then rapidly decreases to $\sim-5 \%$ due to changes in $\delta^{13} \mathrm{C}$ of volcanic $\mathrm{CO}_{2}$ driven by carbon cycling processes in the mantle. Model results reproduce trends observed in the geologic record. Namely, the positive Lomagundi excursion has been observed to be followed by the negative Shunga-Francevillian excursion [2]. Interestingly, this behavior is also observed at the end of the "Boring Billion", with broad a positive excursion punctuated by negative excurions such as the Bitter Springs and Shuram anomalies. If increased weathering and $\mathrm{CO}_{2}$ emissions are prescribed in the model during times of supercontinent break-up, the model reasonably reproduces the $\mathrm{C}$ isotope record and oxygen levels of the entire Protezoic. Results provide a new interpretation of the $\delta^{13} \mathrm{C}$ record and higlight the importance of considering non-constant $\delta^{13} \mathrm{C}$ for volcanic $\mathrm{CO}_{2}$ emissions through time.

[1] Eguchi, et al. 2020. Nature Geoscience

[2] Melezhik, et al. 2015. Earth Science Reviews 